\title{
Utilization of fluorescence images in chlorophyll in Cirebon waters, Indonesia
}

\author{
Brian Dika Praba P Cahya ${ }^{1 *}$, Susanna Nurdjaman ${ }^{1,2}$, Khalid Haidar Dzar Al-Ghifari ${ }^{1}$, Syarifudin Nur ${ }^{1}$, Afif \\ Prabowo Jatiandana ${ }^{1}$ and Destika Agustina Widiawan ${ }^{1}$ \\ ${ }^{1}$ Earth Science Master Program, Bandung Institute of Technology, Bandung, West Java, Indonesia \\ 2 Department of Oceanography, Faculty of Earth Sciences and Technology, Bandung Institute of Technology, \\ Bandung, West Java, Indonesia
}

${ }^{*}$ Corresponding author: briandika@students.itb.ac.id

\begin{abstract}
Satellite is one of the tools used to detect chlorophyll concentration. MODIS chlorophyll concentrations appears to be disturbed by colored dissolved organic matter (CDOM). The fluorescence approach can represent the chlorophyll concentration near the coast more accurately. The data for this study was obtained from satellite Aqua MODIS Level 2 which consisted of MODIS chlorophyll, MODIS fluorescence data, and Observation data. The data was taken on 6 September 2020 in Cirebon Waters. Results of the chlorophyll concentration field data ranged from $0.64 \mathrm{mg} \mathrm{m}^{-3}-4.26 \mathrm{mg} \mathrm{m}^{-3}$. Estimation of chlorophyll concentrations using the standard chlorophyll method ranged from $2.55 \mathrm{mg} \mathrm{m}^{-3}-7.20 \mathrm{mg} \mathrm{m}^{-3}$ and the chlorophyll concentrations using the fluorescence method were $2.58 \mathrm{mg} \mathrm{m}^{-3}-3.5 \mathrm{mg} \mathrm{m}^{-3}$. Comparison of field data with satellite images is better with the florescence method than the standard MODIS chlorophyll technique, with an error of $47.8 \%$ for fluorescence and $235.5 \%$ for the standard MODIS chlorophyll.
\end{abstract}

Keywords: Aqua MODIS imagery, Chlorophyll, Cirebon Waters, Fluorescence.

\section{Introduction}

Chlorophyll is one of the indicator of health of marine ecosystem as it reflects the abundance of phytoplankton (Nazeer and Nichol, 2016). Satellites are among the tools used in detecting chlorophyll (Behrenfeld and Falkowski, 1997). Measurements of chlorophyll can be done using the Moderate Resolution Imaging Spectroradiometer (MODIS) and other satellite tools with band spectral support (Gower and Borstad, 1990; Letelier and Abbott, 1996). However, in coastal areas the use of the OC3M algorithm (McClain et al., 2000), shows higher values due to the presence of dissolved organic matter, and possible complications from suspended matter. In some areas, fluorescence satellite measurements for chlorophyll detection provide a better estimate. Gower et al. (2013) and Gower and King (2012) emphasized that fluorescence can still be detected in conditions of low chlorophyll concentration, so that this method can be applied more accurately. Fluorescence is part of the light that is absorbed by phytoplankton and then re-emitted. Research conducted by Timmermans et al. (2008) showed that the fluorescence correlation with chlorophyll in water sampling I was lesser than in the water in sampling II. Fluorescence gives good results for the latter. Cirebon waters have rivers that flow from industrial areas, fishponds, and ports. This causes an impact on CDOM in the areas near the coast and estuaries. The amount of discharge coupled with the surrounding human activities can negatively affect the waters.

\section{Materials and Methods}

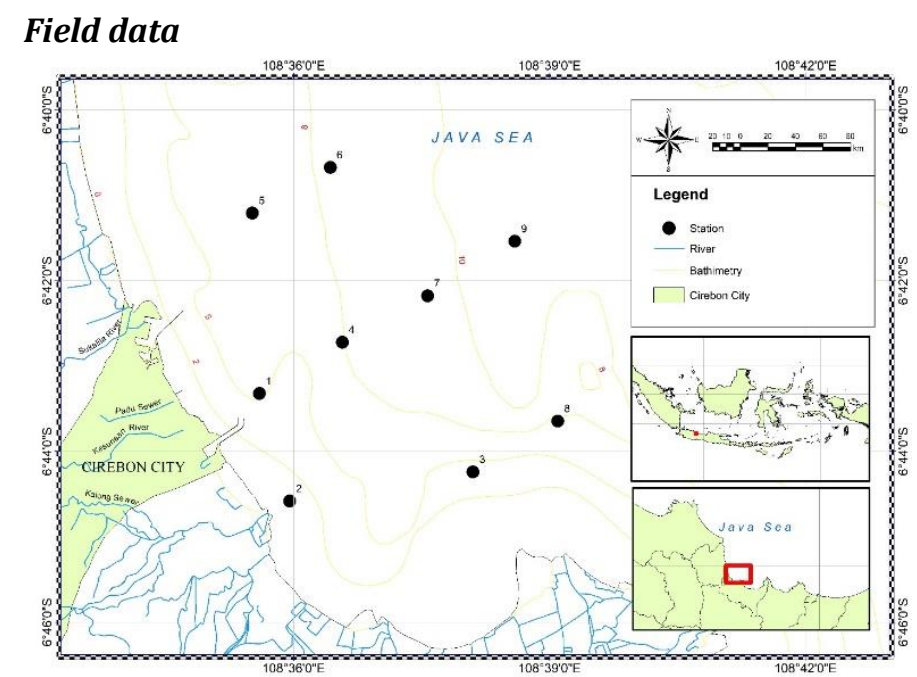

Figure 1. Map of study location.

Surveys were conducted in Cirebon, Indonesian (Figure 1) on 6 September 2020. One liter of seawater samples were collected at 9 observation points. Samples were put into HDPE bottles which were protected from sunlight and stored in a coolbox. The sample was then filtered using Whatman cellulose paper assisted vacuum pump. Before filtration the Whatman cellulose paper was dripped in $1 \mathrm{ml}$ of MgCO3 to bind chlorophyll followed by wrapping in aluminum foil and putting in cool box. The 
sample passed through the porous filter medium was ready for extraction. The process of determining chlorophyll concentration consisted of filtration, extraction, spectrophotometry, and data analysis (Eaton et al., 2005). Chlorophyll extraction was carried out using acetone as a solvent. The concentration of chlorophyll-a was determined by spectrophotometry. The wave lengths used were 664 and $665 \mathrm{~nm}$ after acidification (Eaton et al., 2005).

\section{Satellite data}

Fluorescence and chlorophyll level 2 imagery with a resolution of $1 \mathrm{~km}$ obtained through NASA's real-time Ocean Color was recorded on September 5 2020, for the north coast of Java, Indonesia. MODIS chlorophyll data using OC3M (Ocean Chlorophyll 3-band algorithm MODIS) and MODIS fluorescence calculated from the satellite produced the FLH (fluorescence Line Height) which is the radian of bands 13,14 , and 15 , with the equation algorithm (Abbott and Letelier, 1999):

$F L H=\varphi f * I_{a}$

$I_{a}=I_{0} * \sigma_{I I} * n_{I I}$

$\frac{F L H}{C h l-a}=\varphi f * \frac{I_{a}}{C h l-a}=$ cte $* \varphi f$

Where,

FLH : Fluorescene Line Height $\left(\mathrm{mW} \mathrm{cm}^{-2} \mu \mathrm{m}^{-1} \mathrm{sr}^{-1}\right)$

Фf : Fluorescence Quantum Yield

Ia : Absorption energy

$\mathrm{I}_{0}: \operatorname{PAR}(\mu \mathrm{m})$

$\sigma_{I I}$ : Coefficient of chlorophyll-absorption $\left(\mathrm{mW} \mathrm{cm}^{-2} \mu \mathrm{m}^{-1} \mathrm{sr}^{-1}\right)$

$n_{I I}$ : Satellite chlorophyll-a $\left(\mathrm{mg} \mathrm{m}^{-3}\right)$

Chl-a : Chlorophyll-a concentration $\left(\mathrm{mg} \mathrm{m}^{-3}\right)$

Cte : Factor of coefficient constant $\left(\mathrm{W} \mathrm{m}^{-2} \mu \mathrm{m}^{-1} \mathrm{sr}^{-1}\right)$

[(Abbott and Letelier, 1999)] was used to estimate FLH, and a band-ratio algorithm.

$C a=10^{0.283-2.753 R+1.457 R^{2}+0.659 R^{3}-1403 R^{4}}$

$R=\log _{10}\left(\frac{\operatorname{Rrs}(443)}{\operatorname{Rrs}(550)}>\frac{\operatorname{Rrs}(490)}{\operatorname{Rrs}(550)}\right)$

Method suggested by McClain et al. (2020) was used to estimate the Chl. To reduce errors from satellite sensor digitization/noise, a median value from a $3 \times 3$ box was utilized to filter the image data (Hu et al., 2001). For validation, of each satellite pixel (about $1 \times 1 \mathrm{~km}^{2}$ ), a median value from the multiple field data points was used (Hu et al., 2005) following the regression equation from the field data for mean relative error.

\section{Results and Discussion}

Chlorophyll concentrations from the two images were compared with field data. The error results show a poor correlation with both the chlorophyll image and the fluorescence image (Table 1).

Table 1. Table of error between MODIS fluorescence and chlorophyll.

\begin{tabular}{l|l}
\hline & ERROR \\
\hline FLUORESCENCE & $47.80 \%$ \\
CHLOROPYLL & $235.50 \%$ \\
\hline
\end{tabular}

The error of the estimated image data and the data field is higher than $20 \%$ where the good data has an error range of $10 \%-20 \%$. MODIS chlorophyll image does have poor accuracy for case II waters that are disturbed by the presence of CDOM. Comparison between field data and fluorescence satellite data shows a relatively good error value with an error rate of $47.80 \%$. Although it is quite large value but it is still better when compared to chlorophyll images. This is in line with the research done earlier by $\mathrm{Hu}$ et al. (2005) who noticed the error result in fluorescence and chlorophyll images to be around 76\%, compared to $124 \%$. However, the synoptic patterns seen in MODIS fluorescence data show better compatibility with Chlorophyll field data, regardless of water type. Errors can be caused by changes in the characteristics of seawater if it contains additional substances, such as CDOM, which affects the spectrum of water reflection at the wave lengths used. The difference in the value of chlorophyll concentration taken by ] Aqua MODIS Chlorophyll and Fluorescence is shown in Figure 2. Evidently, there are differences in values when using two different methods.

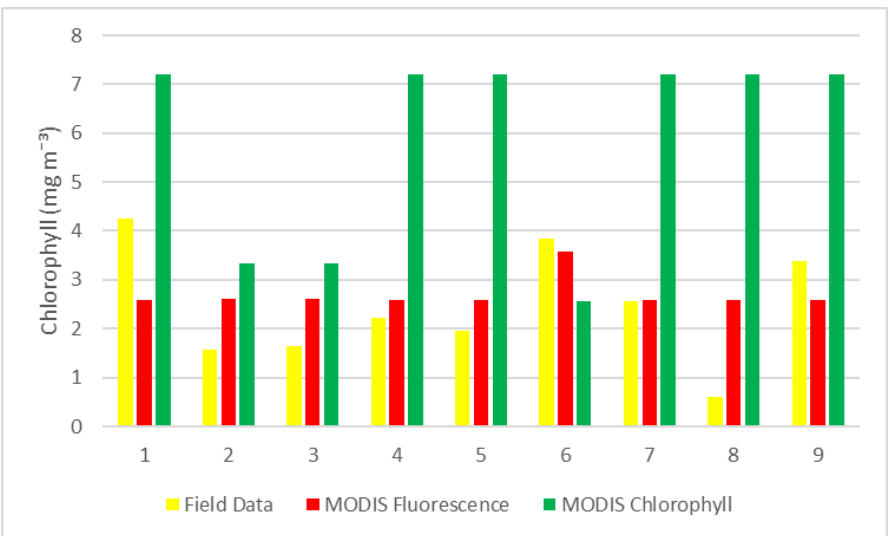

Figure 2. Comparison of chlorophyll concentration. 


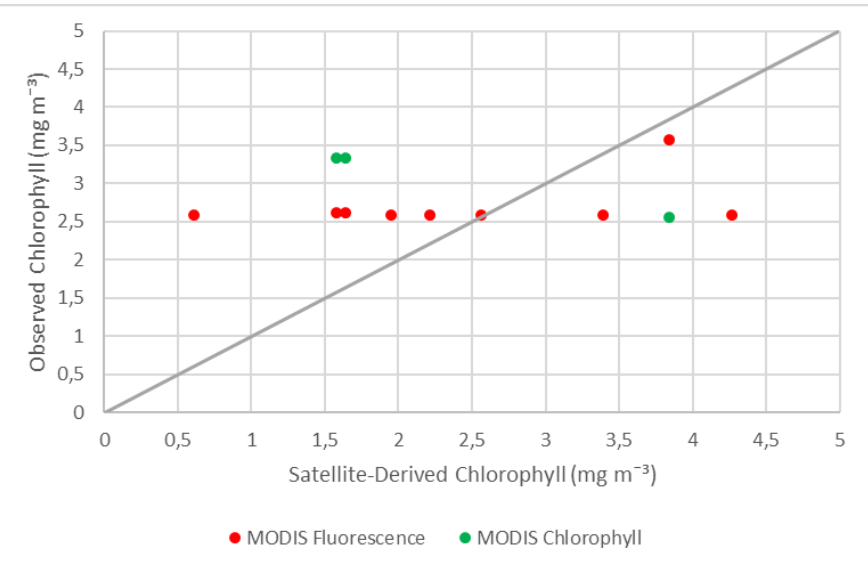

Figure 3. Distribution of MODIS Fluorescence and Chlorophyll values.

The value of chlorophyll concentration in the field data has a range of $0.61 \mathrm{mg} \mathrm{m}^{-3}$ to $4.2 \mathrm{mg} \mathrm{m}^{-3}$, with the highest concentration at station 1 (near the port) and the lowest at station 8 (toward offshore) for MODIS chlorophyll data. The highest concentration is at station 4 (near shore) and the lowest at station 6 (toward offshore) with a range of values from $2.55 \mathrm{mg} \mathrm{m}^{-3}$ to 7.2 mg $\mathrm{m}^{-3}$. The chlorophyll concentrations using fluorescence images obtained the highest results at station 6 (toward offshore) and the lowest at station 2 (near shore) with a range of values from $2.58 \mathrm{mg} \mathrm{m}^{-3}$ to $3.57 \mathrm{mg} \mathrm{m}^{-3}$. The chlorophyll concentration using the chlorophyll image has a much higher range of values compared to the fluorescence image and the chlorophyll concentration from the field data. Ift can be from Figure 3 where most of the overestimate occurred in the good images. The difference that is closer to the chlorophyll concentration value for the in-field data is also seen in Figure 4 where the fluorescence image has a distribution pattern that is closer to the value of chlorophyll field data. Similar observations have been reported earlier (Lara et al., 2017). This strengthens the current observations suggesting that that chlorophyll identification using the fluorescence approach is more accurate than the Aqua MODIS chlorophyll (OC3M) method. In the area near the coast, there are many interventions from rivers and human activities, especially in the rainy season where more sediment material is carried by the river flow to the estuary. Many other materials present in the water interfere with chlorophyll detection.

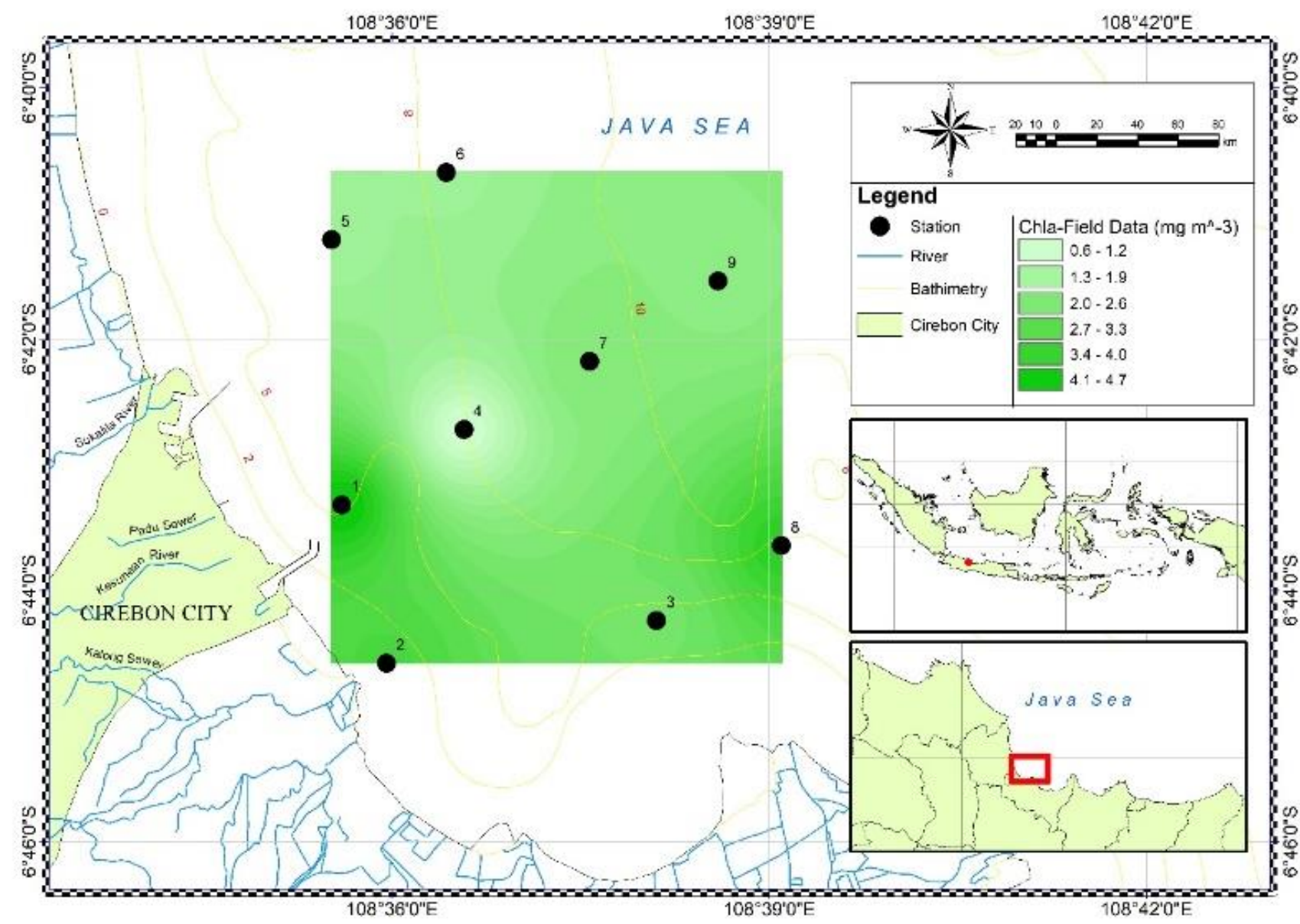

Figure 4. Chlorophyll concentration distribution (field data). 


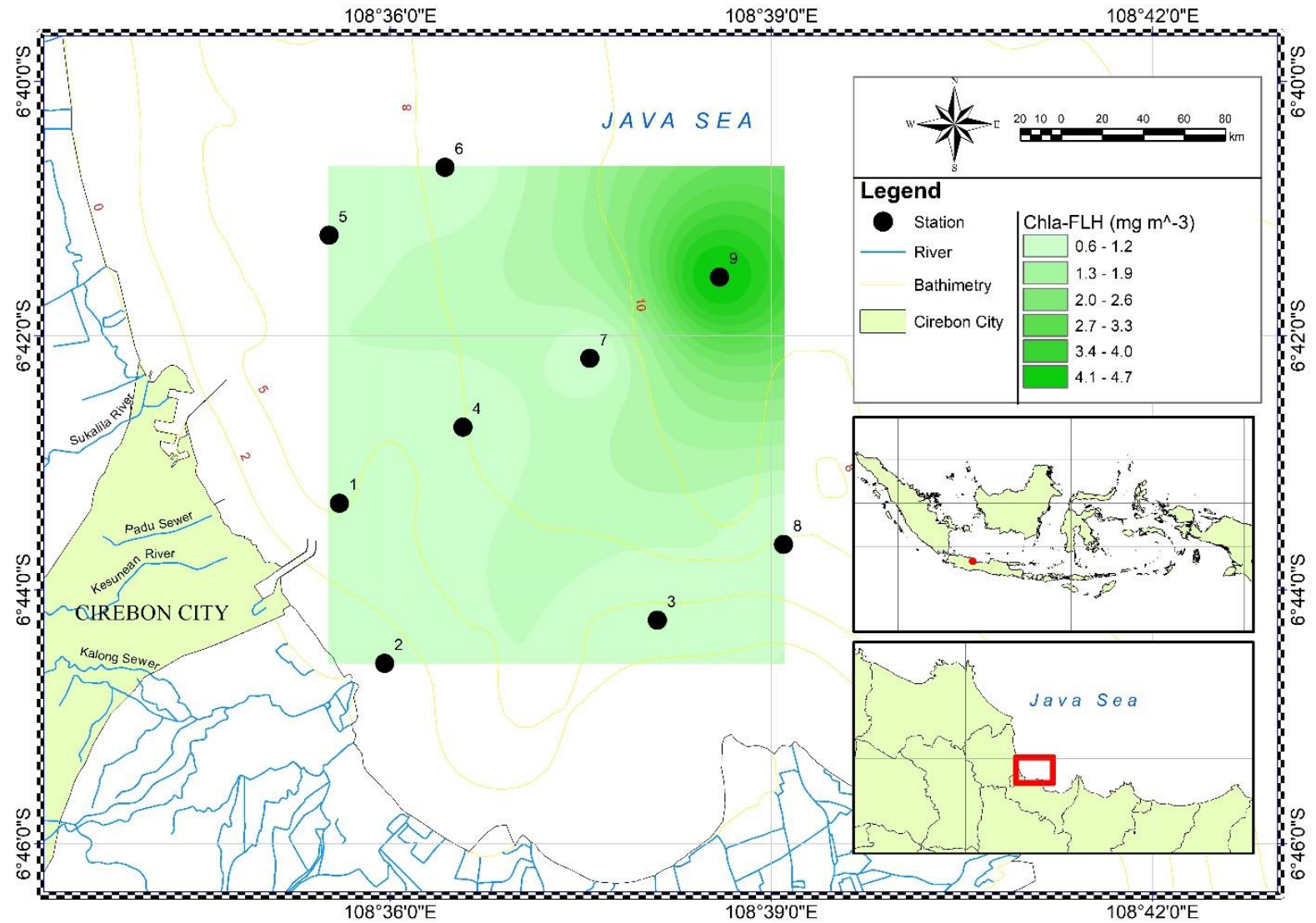

Figure 5. Chlorophyll concentration distribution (Fluorescence method).

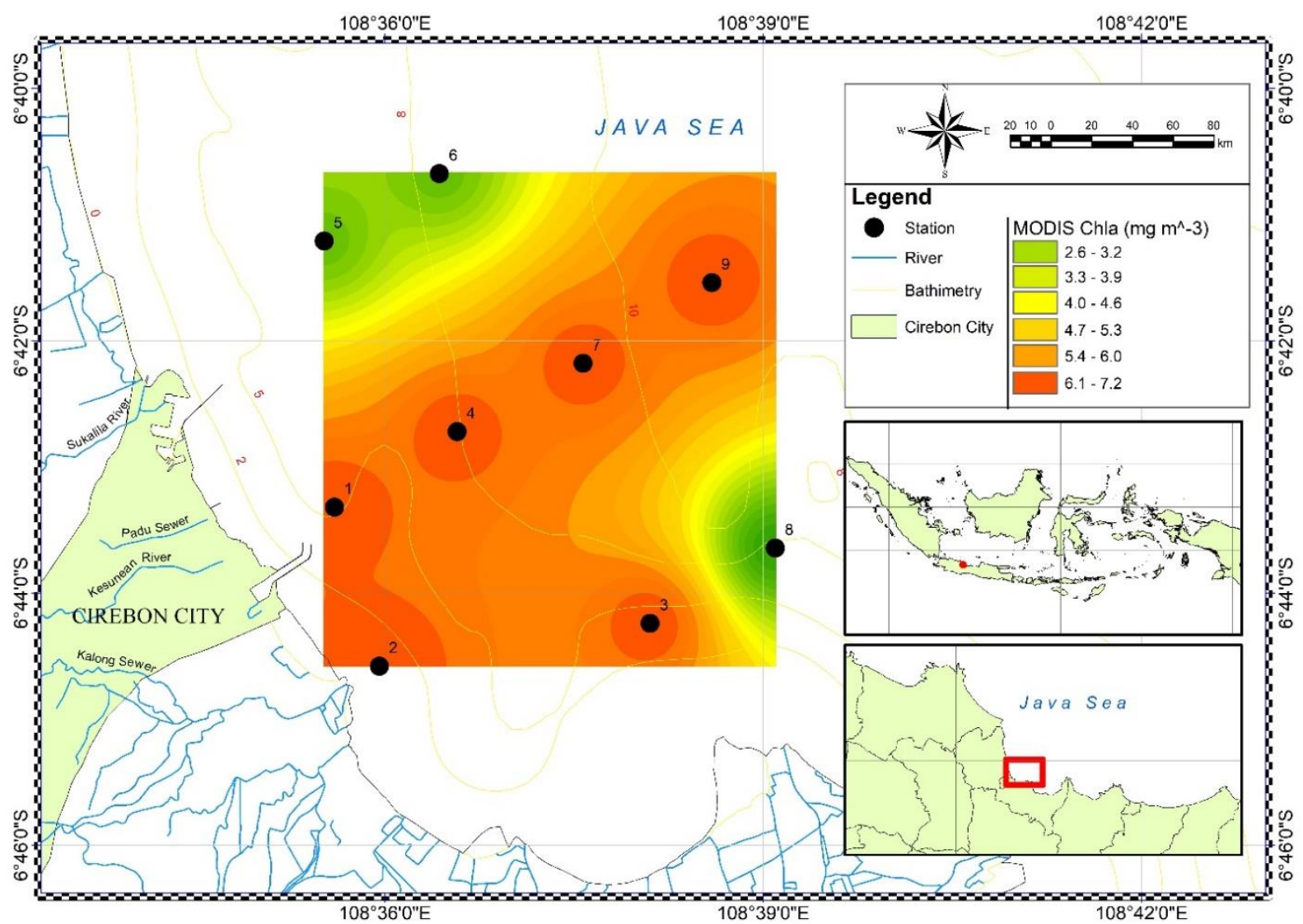

Figure 6. Chlorophyll concentration distribution (MODIS Chlorophyll). 
The chlorophyll concentration values using two images of both fluorescence and chlorophyll currently available from the MODIS satellite sensor are designed to show the spatial distribution of near-surface chlorophyll and phytoplankton pigments. Comparison of the two types of images shows a significant difference, especially in coastal waters. This is is due to the presence of CDOM which causes errors in chlorophyll detection. The most obvious error can be seen in Figure 6, were very different range of values occurs using MODIS chlorophyll images, having a maximum value of up to $7.2 \mathrm{mg} \mathrm{m}^{-3}$ which is indicated by the red distribution pattern that is not present in the distribution pattern in both the Florosens image in Figure 5 and field data in Figure 4. The chlorophyll concentration distribution pattern using the fluorescence image also has no similarity with the chlorophyll concentration distribution pattern in the field data but in the fluorescent image, the range of chlorophyll concentration values is not much different so that the color of the distribution pattern is close to the field data distribution pattern and of course there is no yellow-red color pattern that indicates high chlorophyll concentration. Errors in Chlorophyll detection using fluorescence images even at low levels have been explained by Behrenfeld et al. (2009). These authors stated that fluorescence products can also be affected by clouds coverage and contribute to high signals. Furthermore, fluorescence signals are affected by variations in efficiency of fluorescence of different phytoplankton species or the single species.

\section{Conclusion}

Chlorophyll concentration values using fluorescence images generally follow the chlorophyll concentration distribution pattern from field data. The range of values and patterns of chlorophyll concentration distribution between the fluorescence image and field data in the coastal area of Cirebon (Case II) are similar to the results that a small range of difference between the chlorophyll concentration using the MODIS chlorophyll image, especially in coastal waters affected by CDOM.

\section{Acknowledgments}

This work is part of a master thesis supported by scholarship from the Joint Supervision Korea-Indonesia Marine Technology Cooperation Research Center (MTCRC).

\section{References}

Abbott, M. R., \& Letelier, R. M. (1999). Chlorophyll fluorescence (MODIS product number 20) (ATBD 22). Ocean Color Web Page, 20, 1 42 .

Behrenfeld, M. J., Westberry, T. K., Boss, E. S., O’Malley, R. T., Siegel, D. A., Wiggert, J. D., Franz, B. A., McClain, C. R., Feldman, G. C., Doney, S. C., Moore, J. K., Dall'Olmo, G., Milligan, A. J., Lima, I., \& Mahowald, N. (2009). Satellite-detected fluorescence reveals global physiology of ocean phytoplankton. Biogeosciences, 6(5), 779-794.
Behrenfeld, Michael J., \& Falkowski, P. G. (1997). Photosynthetic rates derived from satellite-based chlorophyll concentration. Limnology and Oceanography, 42(1), 1-20.

Eaton, A.D., Clesceri, L.S., Rice, E.W. and Greenberg, A.E. (2005) Standard methods for the examination of water and wastewater. 21st Edition, American Public Health Association (APHA) Press, Washington, DC.

Gower, J. F. R., \& Borstad, G. A. (1990). Mapping of phytoplankton by solar-stimulated fluorescence using an imaging spectrometer. International Journal of Remote Sensing, 11(2), 313-320.

Gower, J., \& King, S. (2012). Use of satellite images of chlorophyll fluorescence to monitor the spring bloom in coastal waters. International Journal of Remote Sensing, 33(23), 7469-7481.

Gower, J., King, S., Statham, S., Fox, R., \& Young, E. (2013). The malaspina dragon: A newly-discovered pattern of the early spring bloom in the strait of georgia, british columbia, canada. Progress in Oceanography, 115, 181-188.

Hu, C., Carder, K. L., \& Muller-Karger, F. E. (2001). How precise are SeaWiFS ocean color estimates? Implications of digitization-noise errors. Remote Sensing of Environment, 76(2), 239-249.

Hu, C., Muller-Karger, F. E., Taylor, C., Carder, K. L., Kelble, C., Johns, E., \& Heil, C. A. (2005). Red tide detection and tracing using MODIS fluorescence data: A regional example in SW Florida coastal waters. Remote Sensing of Environment, 97(3), 311-321.

Lara, C., Saldías, G. S., Westberry, T. K., Behrenfeld, M. J., \& Broitman, B. R. (2017). First assessment of MODIS satellite ocean color products (OC3 and NFLH) in the inner sea of Chiloé, northern patagonia. Latin American Journal of Aquatic Research, 45(4), 822-827.

Letelier, R. M., \& Abbott, M. R. (1996). An analysis of chlorophyll fluorescence algorithms for the moderate resolution imaging spectrometer (MODIS). Remote Sensing of Environment, 58(2), 215223.

McClain, C. R., Barnes, R. A., Eplee, J., Franz, B. A., Hsu, N. C., Patt, F. S., Pietras, C. M., Robinson, W. D., Schieber, B. D., Schmidt, G. M., Wang, M., Bailey, S. W., \& Werdell, P. J. (2000). Volume 10, SeaWiFS postlaunch calibration and validation analyses, part 2. NASA Technical Memorandum - SeaWIFS Postlaunch Technical Report Series, 11(10), 1-57.

Nazeer, M., \& Nichol, J. E. (2016). Improved water quality retrieval by identifying optically unique water classes. Journal of Hydrology, $541,1119-1132$.

Timmermans, K. R., Van Der Woerd, H. J., Wernand, M. R., Sligting, M., Uitz, J., \& De Baar, H. J. W. (2008). In situ and remote-sensed chlorophyll fluorescence as indicator of the physiological state of phytoplankton near the Isles Kerguelen (Southern Ocean). Polar Biology, 31(5), 617-628. 